\title{
Measurement of wind profiles by motion-stabilised ship-borne Doppler lidar
}

\author{
P. Achtert ${ }^{1}$, I. M. Brooks ${ }^{1}$, B. J. Brooks ${ }^{2}$, B. I. Moat ${ }^{3}$, J. Prytherch ${ }^{1}$, P. O. G. Persson ${ }^{4}$, and M. Tjernström ${ }^{5}$ \\ ${ }^{1}$ Institute for Climate and Atmospheric Science, School of Earth and Environment, University of Leeds, Leeds, UK \\ ${ }^{2}$ National Centre for Atmospheric Science, School of Earth and Environment, University of Leeds, Leeds, UK \\ ${ }^{3}$ National Oceanography Centre, Southampton, UK \\ ${ }^{4}$ Cooperative Institute for Research in Environmental Sciences, University of Colorado and NOAA-Earth System \\ Research Laboratory, Boulder, CO, USA \\ ${ }^{5}$ Department of Meteorology and the Bolin Centre for Climate Research, Stockholm University, Stockholm, Sweden \\ Correspondence to: P. Achtert (p.achtert@leeds.ac.uk)
}

Received: 3 August 2015 - Published in Atmos. Meas. Tech. Discuss.: 10 September 2015

Revised: 9 November 2015 - Accepted: 16 November 2015 - Published: 30 November 2015

\begin{abstract}
Three months of Doppler lidar wind measurements were obtained during the Arctic Cloud Summer Experiment on the icebreaker Oden during the summer of 2014. Such ship-borne Doppler measurements require active stabilisation to remove the effects of ship motion. We demonstrate that the combination of a commercial Doppler lidar with a custom-made motion-stabilisation platform enables the retrieval of wind profiles in the Arctic atmospheric boundary layer during both cruising and ice-breaking with statistical uncertainties comparable to land-based measurements. This held true particularly within the atmospheric boundary layer even though the overall aerosol load was very low. Motion stabilisation was successful for high wind speeds in open water and the resulting wave conditions. It allows for the retrieval of vertical winds with a random error below $0.2 \mathrm{~m} \mathrm{~s}^{-1}$. The comparison of lidar-measured wind and radio soundings gives a mean bias of $0.3 \mathrm{~m} \mathrm{~s}^{-1}\left(2^{\circ}\right)$ and a mean standard deviation of $1.1 \mathrm{~m} \mathrm{~s}^{-1}\left(12^{\circ}\right)$ for wind speed (wind direction). The agreement for wind direction degrades with height. The combination of a motion-stabilised platform with a low-maintenance autonomous Doppler lidar has the potential to enable continuous long-term high-resolution shipbased wind profile measurements over the oceans.
\end{abstract}

\section{Introduction}

Profiles of wind speed and direction are one of the most fundamental quantities for meteorological studies. Radio soundings are still the primary source of global wind profiles (WMO, 2014); however, unless exceptional measures are taken to enable simultaneous reception from multiple sondes, they can only provide a time resolution of the order of hours. This may be adequate to provide a reference measurement of general conditions, but for detailed studies of boundary layer processes continuous and much-higher-time-resolution wind profiles are required. Furthermore, radio-sounding stations for routine operational observations are mostly land-based. Observations at remote sites are very sparse and almost nonexistent over the oceans. Any additional observations in datasparse regions are valuable to improve the initial conditions for numerical weather forecasts (Houchi et al., 2010; WMO, 2014; Baker et al., 2014) and for assimilation into reanalysis products for climate research (e.g. Dee et al., 2011).

Over the ocean, remote sensing with a ship-based Doppler lidar provides an attractive alternative to radio soundings for obtaining profiles with a high time resolution (Tucker et al., 2009; Baker et al., 2014). However, a number of technical challenges must be overcome to obtain high-quality measurements. Ship motion - both its mean horizontal velocity when underway and the high-frequency motions induced by waves and, in this study, ice-breaking - can introduce a mean bias and increase the random error of the raw measurements on 
a range of temporal scales. These errors may even be larger than the wind velocity being measured. In order to correct for the effects of ship motion, the constantly changing orientation and motion of the measurement platform must be compensated for. This can be done either by measuring the ship's motion and correcting for this after the fact or by actively stabilising the instrument for these motions. If the time taken to make a single along-beam Doppler velocity measurement is long enough for the ship motion to change significantly then active motion stabilisation of the instrument is required. This is why only a few studies have used Doppler lidar on ships (Hill et al., 2007; Wolfe et al., 2007; Pichugina et al., 2012). Improvements in technology along with decreasing costs make this an increasingly attractive approach.

Wolfe et al. (2007) and Pichugina et al. (2012) report on a deployment of the NOAA High Resolution Doppler Lidar (HRDL) at sea during the New England Air Quality Study in 2004, along with the first use of a motion compensation system. The motion system combined GPS data with six-axis accelerometers and rate gyros integrated over time to determine the orientation and motion of the lidar in real time. This information was then used to actively compensate for the orientation of the lidar's scanning unit for the ship's motion (Hill et al., 2007). The platform velocity component along the lidar beam was calculated and subsequently removed from the Doppler velocity measurement. A pointing accuracy of order $1^{\circ}$ was achieved under typical conditions during the cruise. Subsequent deployments (Tucker et al., 2009) improved on this, achieving an accuracy of $\approx 0.5^{\circ}$. The estimated noise introduced into each line-of-sight velocity measurement by the motion correction was $0.3 \mathrm{~m} \mathrm{~s}^{-1}$; averaging over a 3 min interval reduced this to $0.015 \mathrm{~ms}^{-1}$, with a mean bias of $0.05 \mathrm{~m} \mathrm{~s}^{-1}$ (Pichugina et al., 2012).

Here we present measurements with a motion-stabilised commercial scanning Doppler lidar. Lacking real-time control of the scanning head orientation, as used by Wolfe et al. (2007) and Pichugina et al. (2012), we mount the lidar as a whole in a motion-stabilised platform. The instrument was operated nearly continuously over a period of 3 months on a ship in the Arctic Ocean during the summer and autumn of 2014. The wind measurements are compared to 6-hourly radio soundings.

\section{Measurements}

The measurements presented here are drawn from the Arctic Cloud Summer Experiment (ACSE), part of the SwedishRussian-US Arctic Ocean Investigation on ClimateCryosphere-Carbon Interactions (SWERUS-C3), which undertook a 3-month-long cruise on the icebreaker Oden. Sailing from Troms $\emptyset$, Norway, on 5 July 2014, the cruise followed the Siberian Shelf to cross the Barents, Kara, Laptev, and East Siberian seas to arrive in Barrow, Alaska, on $19 \mathrm{Au}-$ gust 2014. The return leg departed Barrow on 20 August
Table 1. System parameters of the HALO Doppler lidar.

\begin{tabular}{ll}
\hline Wavelength & $1.55 \mu \mathrm{m}$ \\
Pulse repetition rate & $15 \mathrm{kHz}$ \\
Sampling frequency & $50 \mathrm{MHz}$ \\
Points per range gate & 6 \\
Number of pulses averaged & 30000 \\
Averaging time & $2 \mathrm{~s}$ \\
Range resolution & $18 \mathrm{~m}$ \\
Focus & Infinity \\
Weight & $163 \mathrm{~kg}$ \\
\hline
\end{tabular}

2014 and followed a similar route, slightly further north, back to Troms $\varnothing$, arriving on 5 October 2014 (Fig. 1). The primary objective of ACSE was to study Arctic clouds and their relation to tropospheric vertical structure, meridional transport and the surface energy balance for a variety of surface conditions, from open ocean, through marginal ice and into dense pack ice. ACSE ran an extensive suite of in situ and remote-sensing instrumentation throughout the full 3 months of the cruise (Tjernström et al., 2015). Here, we focus on measurements with a scanning Doppler lidar and 6-hourly radio soundings.

\subsection{Doppler lidar}

The lidar used here is a HALO Photonics Stream Line scanning micro-pulsed Doppler lidar (http://halo-photonics.com/; Pearson et al., 2009) that was located on the roof of a container above the laboratory space on the foredeck of Oden (Fig. 2, left) at a height of $12 \mathrm{ma.s.1}$. The instrument operates at a wavelength of $1.55 \mu \mathrm{m}$ and uses cloud droplets and aerosols as a tracer for air motion. Cloud layers with significant droplet concentrations produce full signal attenuation, prohibiting the acquisition of data above. Such liquid layers were frequently found near 400-500 ma.s.1. in this Arctic marine environment. The lidar's range resolution is $18 \mathrm{~m}$, with 533 range gates and a first measurement at $18 \mathrm{~m}$; the Doppler velocity resolution is $0.038 \mathrm{~m} \mathrm{~s}^{-1}$. An overview of the system parameters is presented in Table 1. Throughout the cruise the lidar was configured to undertake several different scan patterns on a fixed cycle. The wind profile scan ran every $10 \mathrm{~min}$, using a five-point measurement: a vertical beam and four off-vertical measurements at an elevation angle of $70^{\circ}$ and azimuth angles at $90^{\circ}$ increments. The measurement of velocity along each beam is comprised of 30000 pulses at $15 \mathrm{kHz}$ and is thus an average over a $2 \mathrm{~s}$ interval. The time taken for the scanning head to move between consecutive beam positions is also approximately $2 \mathrm{~s}$. All the individual measurements used in the calculation of a single wind profile thus take place within a period of approximately $20 \mathrm{~s}$. 


\subsection{Ship-motion stabilisation}

The lidar was stabilised against the pitch and roll of the ship by mounting it within a specially constructed motionstabilised frame (Fig. 2, right). To minimise the torque required, the whole system is balanced so that the axes of rotation pass through the centre of mass of the instrument. The motion of the ship and of the lidar are measured with two Xsens MTi-700-G attitude and heading reference system (AHRS) sensors rigidly mounted to the outer- and innermost frames, respectively. The motion-control algorithm takes the raw measurements of the rates of rotation for pitch and roll from the ship-frame sensor (nominal accuracy: $0.003^{\circ}$ at $10 \mathrm{~Hz}$ ). It drives servo motors at the same rate but in the opposite direction to hold the inner frame steady against the pitch and roll of the ship. This will maintain the orientation with respect to the horizontal that it had when the system started up. In order to force the inner frame towards the horizontal, the specified rates of rotation are modified by the addition of factors proportional to the absolute pitch and roll of the inner frame. The measurement of the inner-frame attitude uses the solution calculated internally by the Xsens AHRS via a proprietary algorithm which combines all its raw measurements using a Kalman filter (nominal accuracy: $0.2^{\circ}$; precision: $0.05^{\circ}$ ). The complete measurement and control cycle runs at $10 \mathrm{~Hz}$. Both the lidar data logging system and the motion-control system are synchronised hourly to UTC via the ship's time server. Details on the motion-correction algorithm are given in Appendix A.

Approximately half of the ACSE cruise took place in sea ice where the ship's pitch and roll are modest (typically less than $2^{\circ}$ ) but ship motions can be sudden when breaking ice; the other half was in open water, sometimes near the ice edge and other times hundreds of kilometres distant. Some extensive periods during the second leg were spent in open water under conditions of moderately high winds (10 $\mathrm{m}$ winds up to $17 \mathrm{~m} \mathrm{~s}^{-1}$ ) and wave heights up to several metres. The Oden is designed primarily for working within sea ice and lacks a keel; it thus has rather poor stability in rough seas and suffers substantial roll motions. Figure 3a shows a short portion of the time series of roll angles for the ship and the motion-stabilised lidar from 18 September, during the period of roughest seas encountered, when the greatest ship motion was experienced. The probability distribution of lidar roll angle for the $1 \mathrm{~h}$ period with greatest ship roll is shown in Fig. 3b. The maximum ship roll approaches $\pm 8^{\circ}$ with a period of approximately $8.5 \mathrm{~s}$. The motion-stabilised frame keeps the lidar within $0.3^{\circ}$ of horizontal $96.5 \%$ of the time, and within $0.5^{\circ}$ of horizontal $99.3 \%$ of the time. At no point does the lidar roll angle exceed $0.9^{\circ}$.

The residual attitude and three-dimensional velocity of the stabilised inner frame were calculated and combined with the lidar beam orientation to correct the line-of-sight Doppler velocity measurement for the ship's velocity along the beam. The largest tilts were associated with rotation of the lidar

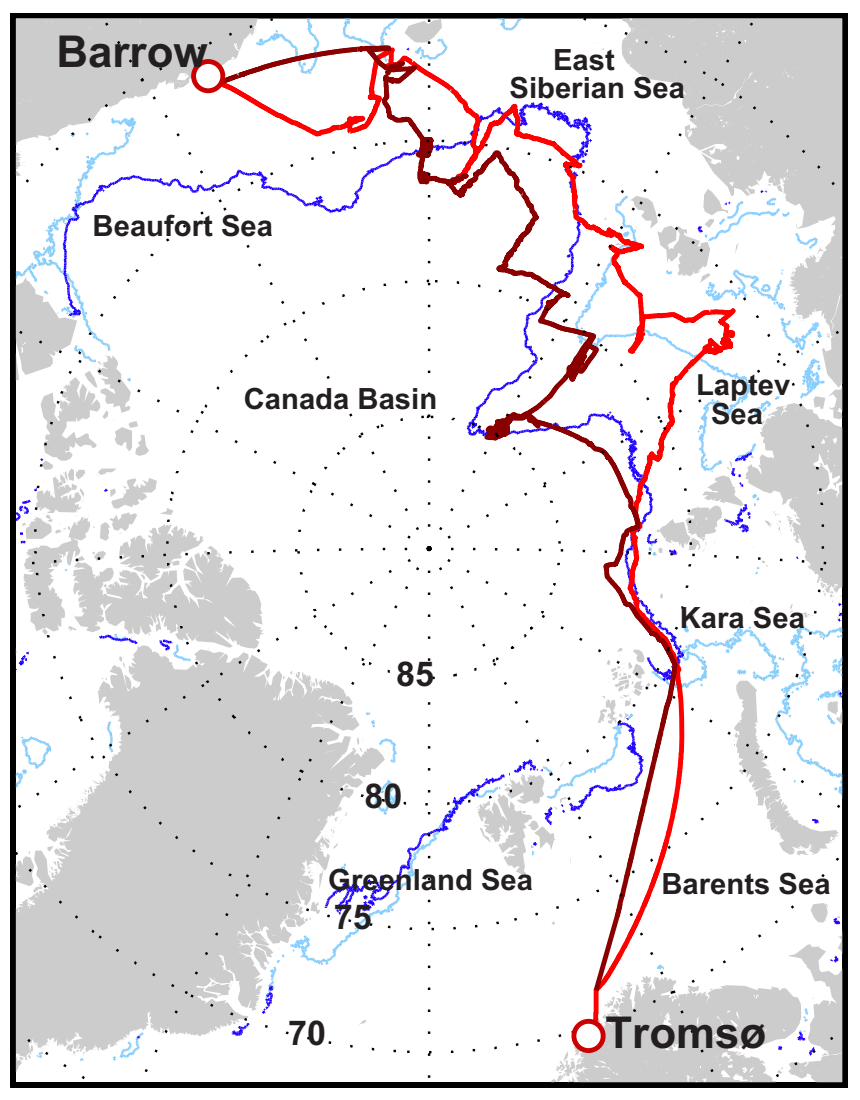

Figure 1. Cruise track of the legs from Troms $\varnothing$ to Barrow (red) and back (brown). Ice edges at the times of start and end of the cruise are shown in light and dark blue, respectively.

head prior to each new measurement. This changed the centre of mass, inducing a small rotation before the motion-control and logging system detected and compensated for this. In principle the complete platform attitude and velocity solution could be obtained directly from the internal solution of the Xsens AHRS; however, we had no opportunity to calibrate the magnetic field sensors for the hard-iron distortions induced by the ship, and the Xsens compass heading thus suffered significant errors. We therefore utilised a combination of the high-frequency attitude and motion calculated from the raw Xsens AHRS measurements of accelerations (nominal accuracy: $2.5 \times 10^{-4} \mathrm{~m} \mathrm{~s}^{-1}$ at $10 \mathrm{~Hz}$ ) and rotation rates, and low-frequency horizontal velocity and heading from the ship's navigation data; the latter are derived from a GPS and gyro compass and have typical accuracies of order $0.02 \mathrm{~m} \mathrm{~s}^{-1}$ for velocity and $0.5^{\circ}$ for heading. We calculate attitude and velocity following the complimentary filtering approach of Edson et al. (1998); this method is routinely used to motioncorrect ship-borne turbulence measurements (e.g. McGillis et al., 2001; Brooks, 2008; Norris et al., 2012; Yang et al., 2014; Drennan et al., 2014; Landwehr et al., 2015; Prytherch et al., 2015). The ship's mean horizontal velocity when underway can approach $6 \mathrm{~m} \mathrm{~s}^{-1}$; the wave-induced velocity per- 

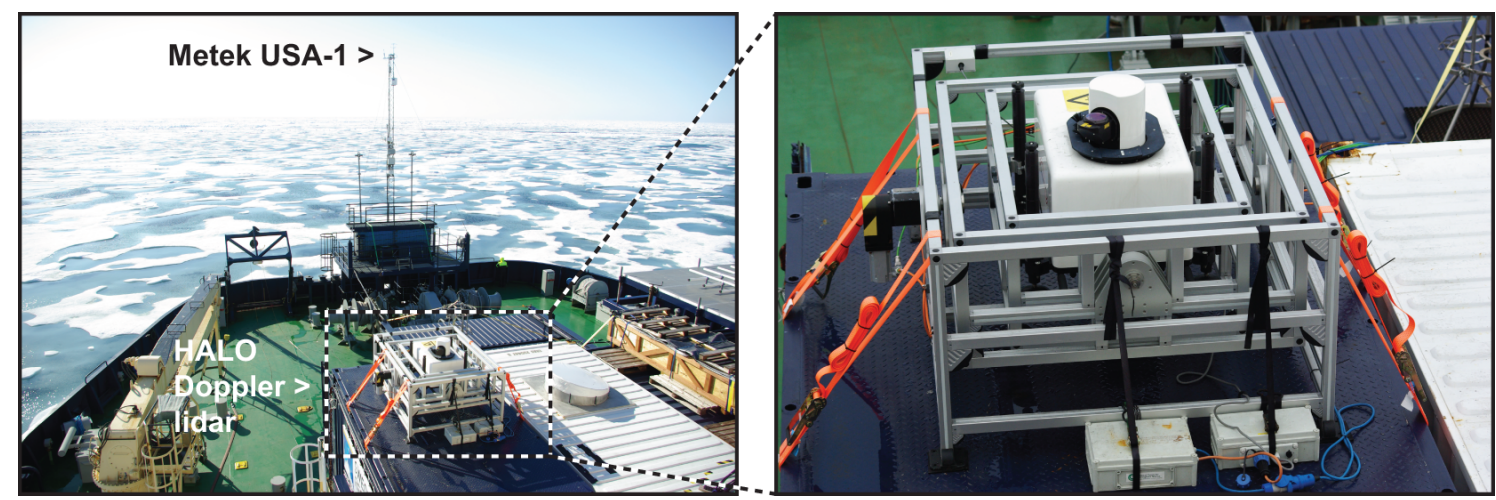

Figure 2. Oden foredeck (left) showing the lidar mounted within its motion-stabilised platform and (right) the Metek USA-1 sonic anemometer mounted on a mast over the bow of the ship.
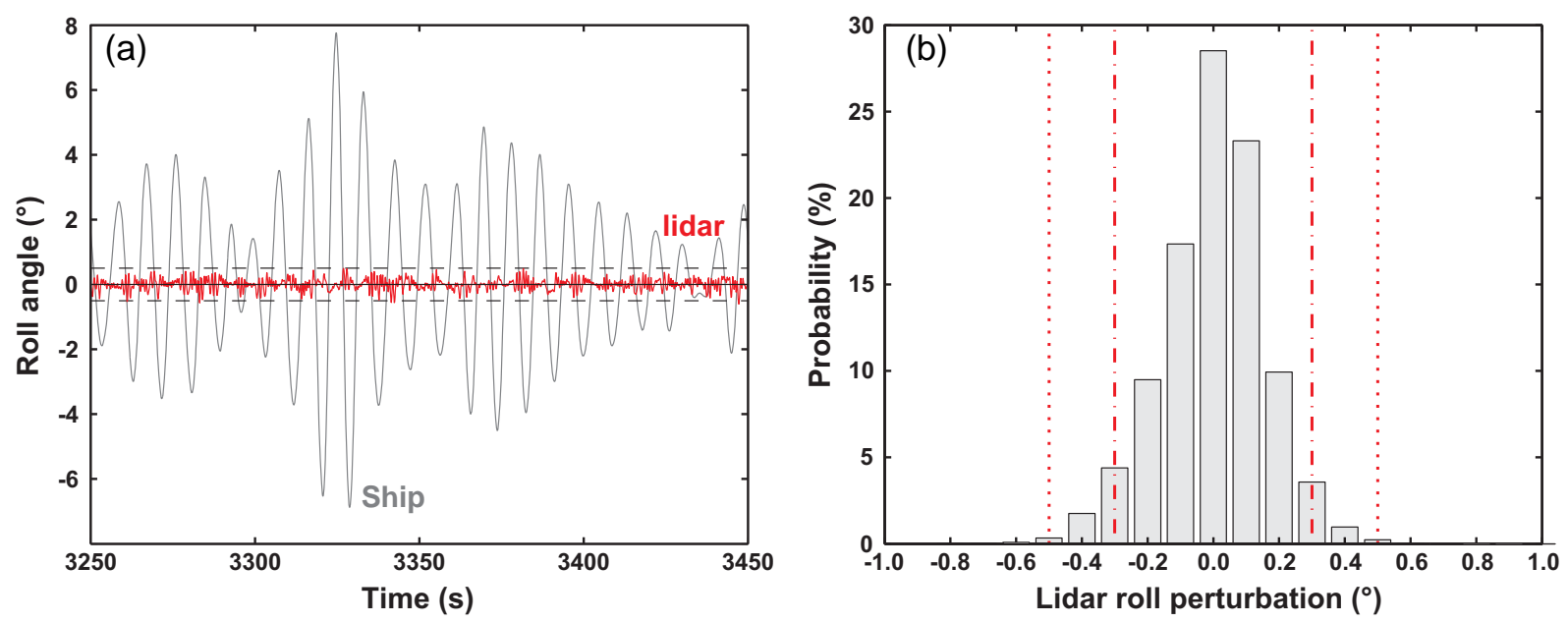

Figure 3. (a) Time series of ship and lidar roll angles on 18 September 2014 (05:54:10-05:57:30). Horizontal dashed lines indicate $\pm 0.5^{\circ}$. (b) Probability distribution of the lidar roll angle over the hour 05:00-06:00 on 18 September 2014 . Red dotted lines indicate $\pm 0.5^{\circ}$; dotdashed lines indicate $\pm 0.3^{\circ}$.

turbations in open water were a maximum of approximately $\pm 0.2 \mathrm{~m} \mathrm{~s}^{-1}$ fore-aft and $\pm 1 \mathrm{~m} \mathrm{~s}^{-1}$ in the vertical and portstarboard.

Because the lidar Doppler velocities are $2 \mathrm{~s}$ averages, we use a corresponding $2 \mathrm{~s}$ averaged platform velocity to correct them; the standard deviation of the individual $10 \mathrm{~Hz}$ platform velocity measurements is also calculated as a quality control measure, in order to flag measurements for which the ship motion changes substantially during the lidar measurement interval and to provide a measure of the noise added to the Doppler winds by the ship motion.

\subsection{Lidar data processing}

The signal-to-noise ratio (SNR) of the Doppler velocity measurement depends on the set-up of the instrument and the availability of aerosols and cloud droplets to reflect the laser beam and act as tracers for atmospheric motion. It is used to separate reliable data from signal noise (Pearson et al., 2009;
Schween et al., 2014). Previous studies using HALO Doppler lidar suggest a SNR threshold ranging from -18.2 to $-23 \mathrm{~dB}$ (Schween et al., 2014; Barlow et al., 2011; Pearson et al., 2009; Lane et al., 2013; Päschke et al., 2015; Hirsikko et al., 2014). However, these values were derived from measurements at midlatitudes, where aerosol load is generally much higher than in the Arctic. Following the approach of Päschke et al. (2015), we derived a conservative SNR threshold of $-16 \mathrm{~dB}$ based on measurements under relatively steady wind conditions with a vertical wind velocity close to zero. Applying this threshold to our Arctic observations leads us to reject around $18 \%$ of data that would be accepted with the commonly used threshold of $-20 \mathrm{~dB}$. This amounts to rejecting a total of $75 \%$ of all individual data points that do not fulfill the SNR criterion. Note that data rejection varies greatly with altitude and atmospheric conditions, and is greatest in the free troposphere, where the majority of rejected data points lie. This rejection rate is particularly great for our Arctic ob- 
servations as we cannot rely on the abundance of scatterers that lead to generally better SNR in observations at midlatitudes. It is likely that changing the telescope focal length from infinity to $1-2 \mathrm{~km}$ (Hirsikko et al., 2014) would improve data collection for conditions of low aerosol load as encountered during ACSE. Unfortunately, the older model of HALO lidar used in ACSE did not allow for overlap adjustment as easily as its successor, and this adjustment was therefore not made.

Wind speed and direction were obtained from the motioncorrected HALO Doppler lidar measurements using the fivepoint geometrical wind solution and the four-point sinusoidal fit method both described in Werner (2005), assuming no major changes or air motion occur within the scanning volume (Lane et al., 2013). The vertical wind is retrieved as an independent parameter for the sinusoidal fit (Werner, 2005). For the four-point sinusoidal fit method, we applied the quality assurance criteria described in Päschke et al. (2015); i.e. we tested for horizontal homogeneity of the wind field (Eq. 13 in Päschke et al., 2015, we applied a threshold of $R^{2}>0.95$ ) and the collinearity of the Doppler velocity measurements used within one scan (Eqs. 14 and 15 in Päschke et al., 2015). For the latter, we ensured that measurements with gaps in the azimuth scan larger than $210^{\circ}$ were not included for further data analysis, i.e. scans with fewer than three out of four points available for analysis.

We also investigated the influence of changes in the heading of the ship during individual scan cycles with and without applying the quality assurance criteria of Päschke et al. (2015). These criteria remove any dependence of wind speed on the change in the ship's heading between the first and the last measurement used in the retrieval. The issue will be addressed in more detail in Sect. 3.1.

Continuous wind profiles could be retrieved up to a maximum altitude of $1600 \mathrm{~m}$ a.s.l. during cloud-free conditions. Data coverage is greatest in the lowermost $200 \mathrm{~m}(93 \%)$ and decreases exponentially with height to $13 \%$ at $1000 \mathrm{~m}$. This is less than usually observed with the same type of instrument at midlatitudes (Pearson et al., 2009; Päschke et al., 2015) due to the generally very low aerosol load in the Arctic (e.g. Lannefors et al., 1983; Heintzenberg and Leck, 2012; Birch et al., 2012). However, within the atmospheric boundary layer we yield data coverage comparable to previous studies. The average daytime maximum and minimum atmospheric boundary layer depths during the cruise were 576.3 and $81.4 \mathrm{~m}$, respectively. Averaged over all observations, we found that the maximum height of useful wind data was around $100 \mathrm{~m}$ lower for cloudy (but not fully attenuating) conditions than for cloud-free conditions. Most of the observed clouds showed a base height of $300 \mathrm{~m}$ or less. Fog was frequently observed during the first leg of the cruise, with fewer fog cases encountered during the second leg. Such conditions typically lead to full attenuation of the lidar signal within the fog. The presence of multiple semi-transparent cloud layers allows for measurements of up to $3000 \mathrm{~m}$ on some occasions, leading to data coverage of $5 \%$ at this altitude.

In order to assess the accuracy of the lidar wind retrievals, results have been compared to the 6-hourly radio soundings. We used Vaisala RS92 radiosondes with a nominal ascent rate of $4 \mathrm{~m} \mathrm{~s}^{-1}$. The manufacturer gives a total measurement uncertainty of $0.15 \mathrm{~m} \mathrm{~s}^{-1}$ and $2^{\circ}$ for wind speed and direction, respectively (VAISALA, 2015). Wind profiles from lidar and radio soundings were interpolated to a common height grid. In addition, lidar winds were averaged over at least 2 scans in the first 30 min after the launch of the radiosonde.

\section{Results}

\subsection{Lidar wind evaluation}

Figure 4 shows scatter plots of wind speed and direction for lidar vs. radiosonde using the four-point sinusoidal fit solution at an altitude of $75 \mathrm{~m}$ a.s.l.. The lidar and radiosonde wind directions agree very well for the five-point geometrical wind solution $\left(R^{2}=0.96\right.$, not shown $)$ and the four-point sinusoidal fit $\left(R^{2}=0.99\right.$, see Fig. $\left.4 \mathrm{a}\right)$. Both methods show negligible bias, while a slightly better standard deviation is found for the four-point sinusoidal fit (Table 2).

Extreme outliers (red points in Fig. 4a and b) were determined through the Grubbs test (Grubbs, 1969) and excluded from the linear fits. The values at around 0 and $360^{\circ}$ in Fig. $4 \mathrm{a}$ are related to the periodicity of wind direction and do not represent erroneous measurements per se. The lidar slightly underestimates the radiosondes for winds below about $4 \mathrm{~m} \mathrm{~s}^{-1}$ and overestimates at higher wind speed - by about $2 \mathrm{~m} \mathrm{~s}^{-1}$ at wind speeds of $16 \mathrm{~m} \mathrm{~s}^{-1}$ (Fig. 4b).

Linear fit parameters for both geometric and sinusoidal fits, as well as the number of measurements for the comparisons shown in Fig. 4, are given in Table 2.

Both the five-point geometrical and sinusoidal methods to derive wind speed from the lidar data yield similar results. However, the sinusoidal fit is of advantage for our application as it only requires three input points to provide a solution. This increases the number of measurement intervals that can be used by around $25 \%$. Consequently, sinusoidal fits have been used in the analysis of Doppler lidar measurements during the ACSE cruise. The blue diamonds in Fig. 4a and b represent observations during which the motion-stabilisation platform was not operating. While these are only five individual scans, they do demonstrate that an unstabilised instrument suffers far greater scatter in the measurements.

Figure 5a (blue lines) shows a height-resolved view of the correlation coefficient for the different comparisons between lidar winds and the soundings. The squared correlation coefficient for wind direction is approximately 0.99 and almost constant with altitude up to $400 \mathrm{~m}$ a.s.l., decreasing slightly to approximately 0.97 at $700 \mathrm{~m}$ a.s.l.. Both bias and standard 

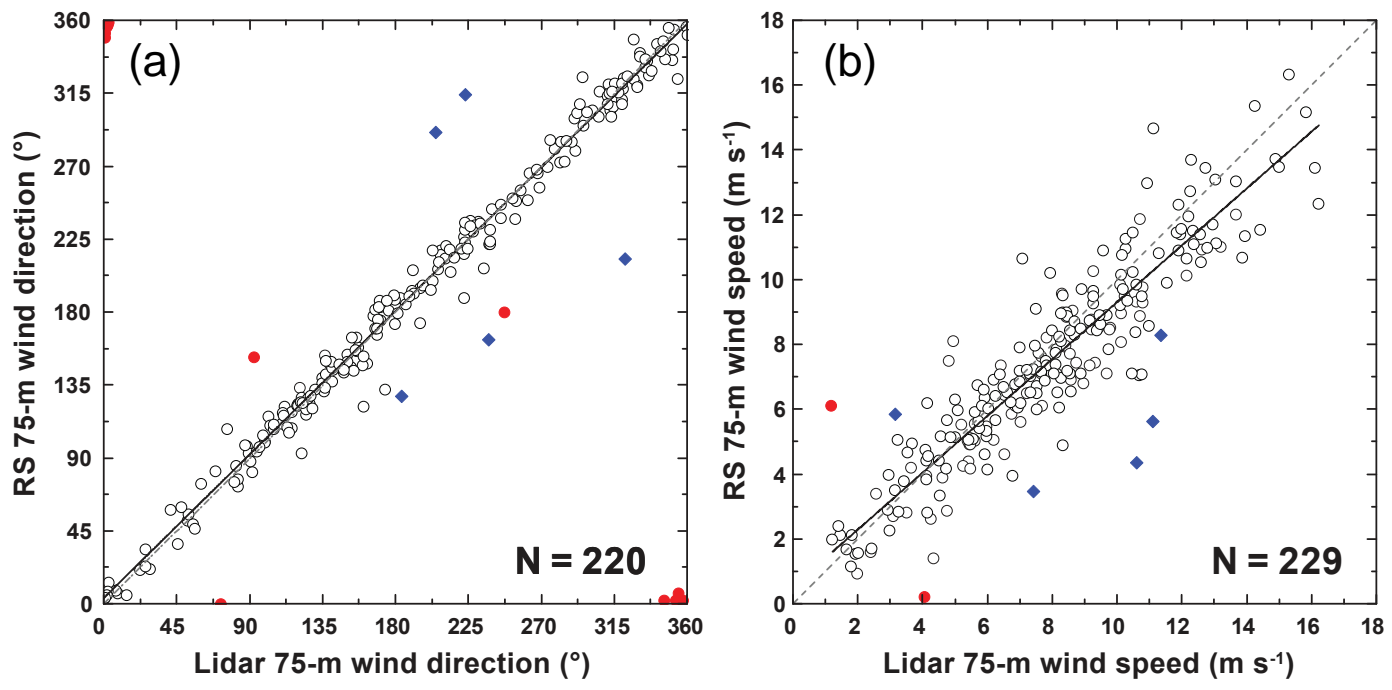

Figure 4. Doppler lidar evaluation: the sinusoidal fit solution is compared to data from radiosondes launched every $6 \mathrm{~h}$ from Oden for (a) wind direction and (b) wind speed. Number of points and linear fit parameters are given in Table 2; red points indicate outliers in wind direction. The blue diamonds show comparison points obtained when the stabilisation platform was turned off.

Table 2. Statistics of the comparison between lidar and radio sounding for a height of $75 \mathrm{~m}$. Normalised RMSE is defined as RMSE divided by the maximum range of the measured values (maximum-minimum).

\begin{tabular}{llrr}
\hline & & Wind speed & Wind direction \\
\hline Geometrical wind solution & $N$ & 175 & 163 \\
& Standard deviation & $1.3 \mathrm{~m} \mathrm{~s}^{-1}$ & $20^{\circ}$ \\
& Bias & $0.5 \mathrm{~m} \mathrm{~s}^{-1}$ & $-1^{\circ}$ \\
& $R^{2}$ & 0.85 & 0.96 \\
& Intercept & $0.71 \mathrm{~m} \mathrm{~s}^{-1}$ & 4.35 \\
& Slope & 0.85 & 0.98 \\
RMSE & $1.2 \mathrm{~m} \mathrm{~s}^{-1}$ & $15^{\circ}$ \\
Sinusoidal fit & $1.7 \%$ & $4.2 \%$ \\
& Normalised RMSE & 229 & 220 \\
& Standard deviation & $1.2 \mathrm{~m} \mathrm{~s}^{-1}$ & $10^{\circ}$ \\
& Bias & $0.4 \mathrm{~m} \mathrm{~s}^{-1}$ & $0^{\circ}$ \\
$R^{2}$ & 0.86 & 0.99 \\
& Intercept & $0.48 \mathrm{~m} \mathrm{~s}^{-1}$ & $3.53^{\circ}$ \\
& Slope & 0.89 & 0.98 \\
& RMSE & $1.1 \mathrm{~m} \mathrm{~s}^{-1}$ & $13^{\circ}$ \\
& Normalised RMSE & $5.9 \%$ & $3.5 \%$ \\
\hline
\end{tabular}

deviation for wind direction increase with altitude (Table 3). This is primarily the result of the drift of the radiosonde and the resulting decrease in collocation of the measurements. For wind speed the squared correlation coefficient's minimum ( 0.86 to 0.89$)$ is a minimum at the lowest altitudes, and it improves with height to values comparable to those for wind direction. Too few data points are available at altitudes higher than $700 \mathrm{~m}$ a.s.l. for an effective comparison.

The squared correlation coefficient for the solution for wind speed improves from 0.86 at 100 to 0.94 at $400 \mathrm{~m}$. In addition, the absolute value of the bias decreases from 0.5 to $0.3 \mathrm{~m} \mathrm{~s}^{-1}$ (Table 3). The change from positive to negative bias with height marks systematically larger wind speed from the radio soundings compared to the lidar measurement. A similar improvement (with respect to values obtained using the quality assurance criterion of Päschke et al., 2015) in the comparison to the radiosonde is obtained when the change in the ship's heading during one scan is restricted to smaller angles of 5 or $10^{\circ}$ rather than $20^{\circ}$. This is expressed by the red and black lines for different cut-off angles presented in Fig. 5. Large changes of the heading of the ship shift the azimuth angles used in the four-point sinusoidal fit and lead 

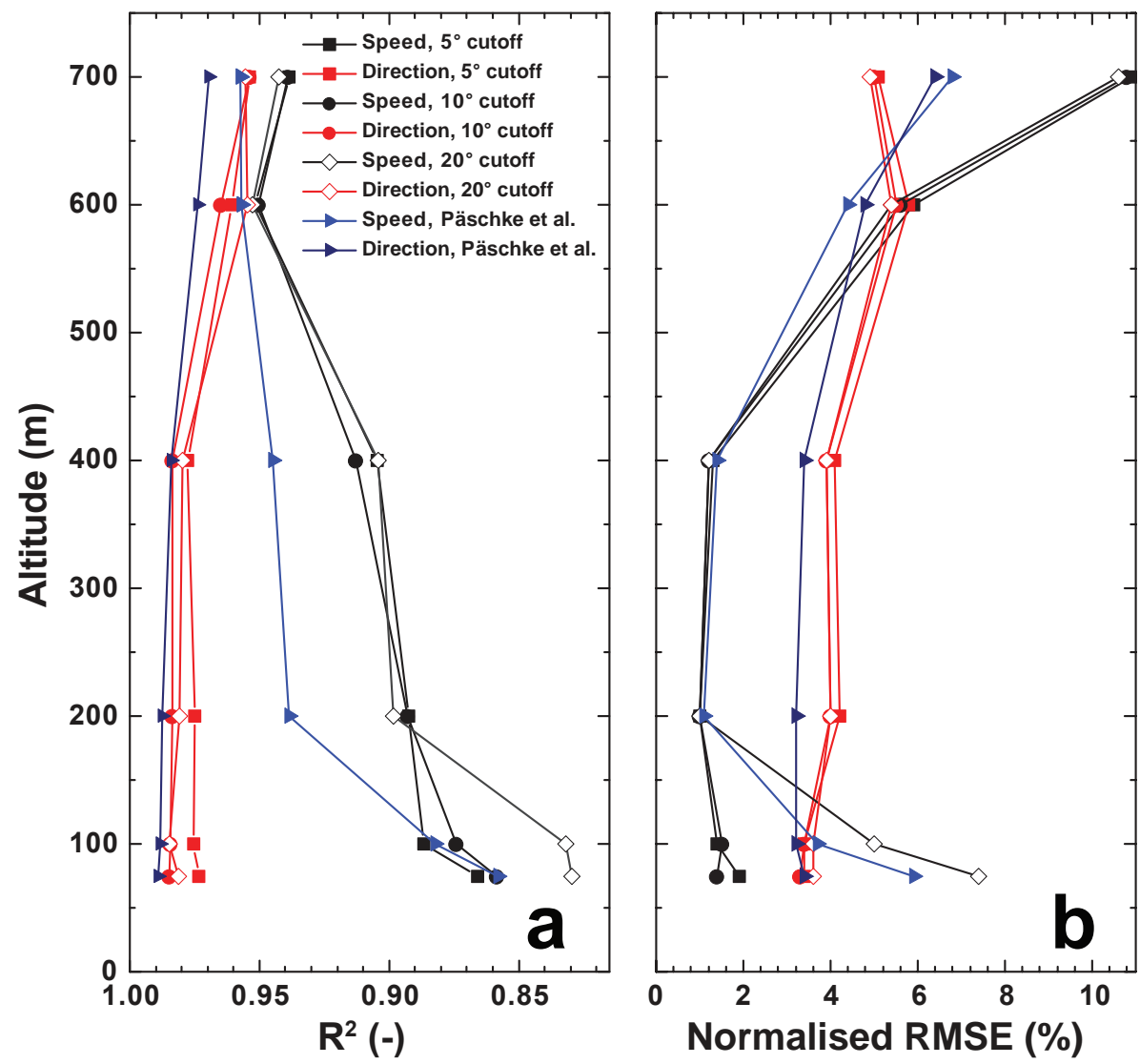

Figure 5. Squared correlation coefficient (a) and normalised RMSA (b) of derived wind speed (black) and wind direction (red) from lidar vs. radiosonde for different altitudes. Squares, circles and diamonds refer to cut-off angles of 5,10 and $20^{\circ}$ in the change of heading of the ship during one scan, respectively. The blue line refers to findings obtained using the quality assurance criteria of Päschke et al. (2015).

Table 3. Statistics of the comparison between lidar and radio sounding at heights of 75, 100, 400, 600, and $700 \mathrm{~m}$.

\begin{tabular}{|c|c|c|c|c|c|c|c|c|c|c|c|c|}
\hline \multirow[b]{2}{*}{ Height (m) } & \multicolumn{6}{|c|}{ Wind speed } & \multicolumn{6}{|c|}{ Wind direction } \\
\hline & 75 & 100 & 200 & 400 & 600 & 700 & 75 & 100 & 200 & 400 & 600 & 700 \\
\hline$N$ & 229 & 226 & 182 & 90 & 47 & 37 & 220 & 219 & 181 & 90 & 43 & 35 \\
\hline $\operatorname{STD}\left(\mathrm{ms}^{-1}\right) /\left(^{\circ}\right)$ & 1.2 & 1.3 & 1.0 & 1.0 & 0.9 & 0.9 & 10 & 10 & 10 & 12 & 13 & 16 \\
\hline $\operatorname{Bias}\left(\mathrm{ms}^{-1}\right) /\left(^{\circ}\right)$ & 0.4 & -0.3 & -0.4 & -0.3 & 0.0 & -0.3 & 0 & 0 & 1 & -1 & 2 & 5 \\
\hline$R^{2}$ & 0.86 & 0.88 & 0.94 & 0.94 & 0.96 & 0.96 & 0.99 & 0.99 & 0.99 & 0.98 & 0.97 & 0.97 \\
\hline Intercept $\left(\mathrm{ms}^{-1}\right) /\left(^{\circ}\right)$ & 0.48 & 0.64 & 0.45 & 0.14 & -0.48 & 0.15 & 3.53 & 5.12 & -0.46 & 0.43 & -5.78 & -12.95 \\
\hline Slope & 0.89 & 0.96 & 1.00 & 1.01 & 1.06 & 1.03 & 0.98 & 0.93 & 0.99 & 1.00 & 1.01 & 1.03 \\
\hline $\begin{array}{l}\text { Normalised } \\
\text { RMSE (\%) }\end{array}$ & 5.9 & 3.7 & 3.2 & 3.4 & 4.4 & 6.8 & 3.5 & 3.2 & 1.1 & 1.4 & 4.8 & 6.4 \\
\hline
\end{tabular}

to non-uniform intervals; this can lead to a degradation of the fit. Fig. 5b shows the normalised root mean square error (RMSE) for the comparison of measurements with lidar and sounding at different altitudes. The strongest difference in normalised RMSE for the wind speed comparison is found at lower levels when using quality assurance according to Päschke et al. (2015) or by restricting the change in the ship's heading. At the uppermost altitudes considered here, using Päschke et al. (2015) provides lower normalised RMSE (7\%) then the other criteria (11\%). The lowest RMSE for wind speed of $1.5 \%$ is found at 200 and $400 \mathrm{~m}$ height. The comparison for wind direction (normalised RMSE of 3.5-5.5\%) shows almost no sensitivity to the quality assurance method and little variation with altitude even though Päschke et al. (2015) performs slightly better.

There are a number of effects that might influence the measurements at low level. The primary source of discrepancy is likely to be the fundamentally different nature of the 


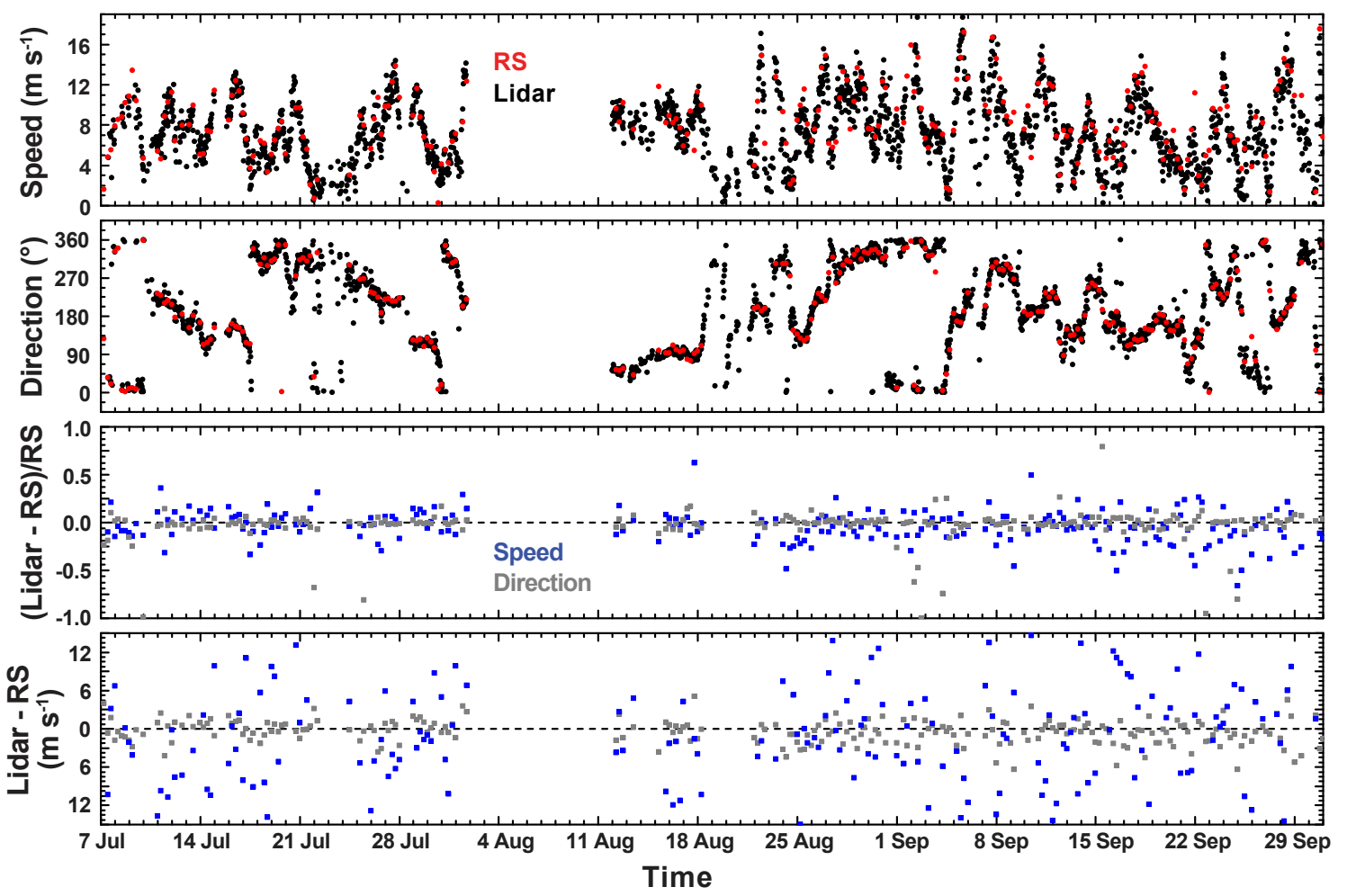

Figure 6. Time series of lidar (black, every $50 \mathrm{~min}$ ) and radiosonde (red, every $6 \mathrm{~h}$ ) wind speed (top) and wind direction (middle) at $100 \mathrm{~m}$ a.s.l. The lower two panels show the relative and absolute difference for wind speed (blue) and direction (grey).

measurements. The radiosonde follows a unique trajectory resulting from the sum of its buoyant ascent rate and the motion of the air it ascends through. Within the atmospheric boundary layer, turbulence superimposes chaotic perturbations about the mean flow; the largest-scale eddies might result in very different trajectories depending on the precise time and location of launch. The lidar, on the other hand, calculates a wind profile from the air motions along each beam, which are separated both in time and in space - increasingly so with increasing altitude. These effects, along with the increasing spatial separation between the radiosonde and the lidar, may also cause the slight decrease in the correlation for wind direction with increasing altitude. An additional source of discrepancies is flow distortion around the ship; this would influence low-level measurements from both, with different effects on each due to their different locations.

The radiosonde will furthermore take time to accelerate to the ambient wind speed following launch, and it can suffer from pendulum motions as the tether unwinds after launch (see Fig. 3 in Marlton et al., 2015). The latter effect can be particularly pronounced during high-wind-speed conditions and might affect the calculation of wind speed from consecutive GPS position estimates. The sondes are also launched close to the ship's superstructure and, depending on the shiprelative wind direction, may have been launched from within the local wind shadow of the ship's superstructure, delay- ing its acceleration to match the wind; for a short while after launch its motion can also be affected by the turbulent wake of the ship. The radiosondes' low-level winds are also affected by the surface winds entered into the proprietary sounding program; these were obtained from a sonic anemometer mounted on the foremast of the ship (Fig. 2), approximately $20.6 \mathrm{~m}$ above the surface $(12.4 \mathrm{~m}$ above the deck). The wind speed measurements are corrected for flow distortion using the results of a computational fluid dynamics (CFD) modelling study of flow over the ship following the approach of Yelland et al. (2002) andMoat et al. (2005); however for relative wind directions from aft, there will remain biases in these measurements.

Time series of wind speed and direction at an altitude of $100 \mathrm{~m}$ as measured with radiosonde and lidar are shown in Fig. 6. The gap from 4 to 12 August 2014 is due to a change in scanning set-up of the lidar; no retrieval of wind speed and direction is possible during this period. During the first leg, the mean horizontal wind speed was $7.2 \mathrm{~m} \mathrm{~s}^{-1}$, while a slightly larger value of $9.0 \mathrm{~m} \mathrm{~s}^{-1}$ was obtained for the second leg. Wind direction showed high variability throughout the cruise. However, extensive periods of northerly and south-easterly winds can be identified. The relative difference presented in the bottom panel of Fig. 6 shows that wind direction generally agrees within $10 \%$. A stronger spread of values is found for the relative difference of wind speed 


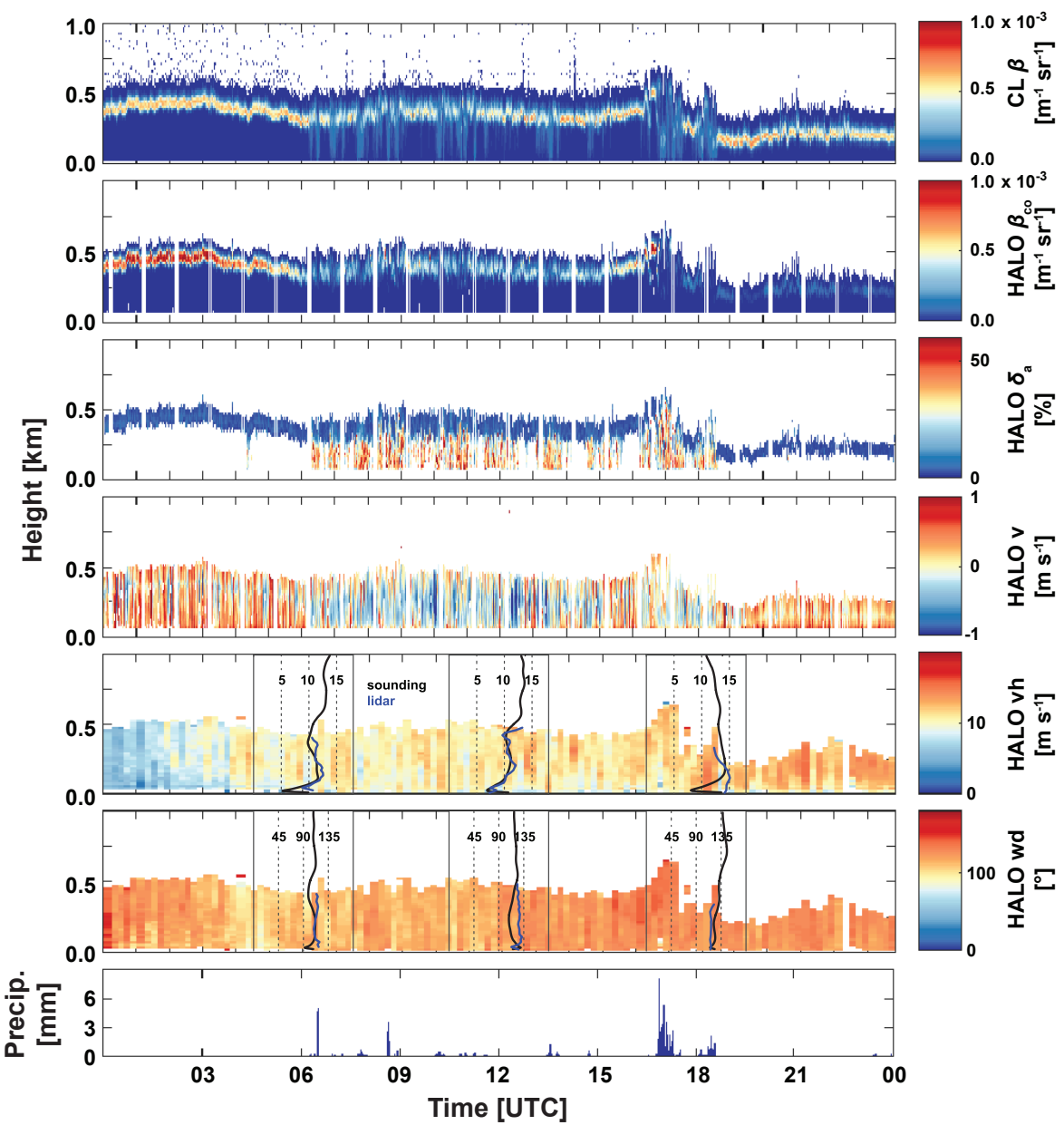

Figure 7. Example measurement of 17 September 2014: calibrated backscatter coefficients from ceilometer (a) and Doppler lidar (b), depolarisation ratio (c), vertical (d) and horizontal (e) wind speed, wind direction (f) from Doppler lidar, and precipitation amount from a precipitation sensor on the ship (g). The profiles in (e) and (f) show the comparison of horizontal wind speed and direction to the radiosondes launched at 06:00, 12:00, and 18:00 UTC. The ship's average speed during that day was 0.5 and $4.5 \mathrm{~ms}^{-1}$ before and after 15:00 UTC, respectively.

with extreme values of up to $50 \%$ difference. For the average wind speed of 6 to $8 \mathrm{~m} \mathrm{~s}^{-1}$ and above, the difference between lidar and radiosonde is below $20 \%$. The mean (median) wind speeds at $100 \mathrm{ma.s.1}$ are $7.9 \pm 3.4(7.7) \mathrm{m} \mathrm{s}^{-1}$ and $8.2 \pm 3.5$ (8.1) $\mathrm{m} \mathrm{s}^{-1}$ for the lidar and radiosonde, respectively. The relative difference in wind speed follows a Gaussian distribution (not shown) that is centred slightly off zero as winds measured by lidar are on average $0.3 \mathrm{~m} \mathrm{~s}^{-1}$ lower than those inferred from the radio soundings. A time series of the absolute differences in wind speed and direction reveals slightly increased scatter in the second part of the cruise during, which higher wind speed has been observed.

A typical measurement day of 17 September 2014 is presented in Fig. 7. Marine stratocumulus was present for the entire day, with cloud base heights descending from 400 to $200 \mathrm{~m}$ during the course of the day. The depolarisation ratio from the Doppler lidar reveals that ice (high values) is precip- itating from liquid water clouds (low values) between 06:00 and 18:00 UTC. This is also in agreement with the measurements of vertical wind speed (negative values equal downward motion due to precipitation) and precipitation rate. Averages of $20 \mathrm{~min}$ of Doppler lidar measurements around the times of radiosonde launches at 06:00, 12:00, and 18:00 UTC are used for a profile-to-profile comparison of wind speed and direction in Fig. 7e and $\mathrm{f}$. No major differences are visible for the height range covered by the Doppler lidar apart from the wind speed in the lowermost $100 \mathrm{~m}$ for the 18:00 UTC sonde.

\subsection{Measurement uncertainty}

Following the approach of Frehlich (2001) and Pearson et al. (2009), an auto-covariance scheme has been used to determine the standard deviation of the vertical wind measure- 
ments with the motion-stabilised lidar during ACSE. The difference between the zeroth lag (first term in the autocovariance) and the first lag gives a measure of the random error. This value has to be compared to the theoretical standard deviation of the instrument. The theoretical standard deviation has been estimated for SNR values between -30 and $16 \mathrm{~dB}$ as described in O'Connor et al. (2010, Eq. 7). We used lidar specifications given in Table 1 and a signal spectral width of $2 \mathrm{~m} \mathrm{~s}^{-1}$ (O'Connor et al., 2010). To determine the standard deviation for observations during ACSE, we only considered wind profiles during relatively steady wind conditions, i.e. during periods for which at least four consecutive lidar wind profiles showed a mean vertical velocity within $\pm 0.25 \mathrm{~m} \mathrm{~s}^{-1}$ of zero.

The observed standard deviation of the vertical velocity as a function of SNR is presented in Fig. 8 together with the theoretical standard deviation calculated as described above. We find a constant random error range between 0.025 and $0.2 \mathrm{~m} \mathrm{~s}^{-1}$ above $-16 \mathrm{~dB}$. This confirms our choice of a conservative SNR threshold of $-16 \mathrm{~dB}$ according to the method of Päschke et al. (2015). SNRs larger than $2 \mathrm{~dB}$ refer to cloud measurements. The error increases for lower SNR as the result of increasing signal noise. The experimental error exceeds the theoretical values but follows the expected change with SNR. Pearson et al. (2009) reported an error between 0.03 and $0.04 \mathrm{~m} \mathrm{~s}^{-1}$ for SNR larger than $-10 \mathrm{~dB}$ and errors that increase up to $0.4 \mathrm{~m} \mathrm{~s}^{-1}$ at $-20 \mathrm{~dB}$. Our findings compare well with Fig. 2c in Pearson et al. (2009). The larger standard deviation we observe in our measurements is likely to be the result of the limitations of the motion stabilisation. This includes residual small perturbations about the horizontal and the necessity of correcting the Doppler velocity measurements for ship motion only as an average over the $2 \mathrm{~s}$ measurement interval; during this time the high-frequency ship motions, induced by waves or ice-breaking, can change significantly.

In addition to the random error we also investigated the measurements of vertical wind speed for systematic errors. To determine the systematic errors of the measurements, we averaged all data for which steady wind conditions prevailed (about 3000 points at $200 \mathrm{~m}$ a.s.l. decreasing down to 200 points at 1000 ma.s.1.). While the average vertical velocity should be close to zero, we derived a mean value of $0.1365 \pm 0.005 \mathrm{~m} \mathrm{~s}^{-1}$ for the height range up to $1000 \mathrm{~m}$ a.s.l. This means that measurements of vertical velocity will be slightly biased upwards. This constant bias could be due to flow distortions of the ship that are discussed below.

There are a number of potential sources of real bias in the measured vertical wind. One is the projection of horizontal wind into the vertical wind speed measurement as the result of imperfect motion stabilisation or misalignment of the lidar and AHRS units; the latter is estimated to be less than $0.5^{\circ}$. A comparison of the output of the internal tilt sensor of the lidar with the XSens motion pack unit was performed during installation to level the two with respect to each other.
If the lidar alignment deviates from the horizontal by 0.3 or $0.9^{\circ}$ (respectively the typical and maximum limits of the motion stabilisation) for a campaign mean wind speed of $8 \mathrm{~m} \mathrm{~s}^{-1}$, the aliasing effect in the vertical wind will be \pm 0.04 or $\pm 0.12 \mathrm{~m} \mathrm{~s}^{-1}$, respectively. A source of a real upward air motion over the lidar is flow distortion over the ship. This is known to be a cause of significant bias in estimates of the mean wind (Yelland et al., 1998; Moat et al., 2006b, a; Moat and Yelland, 2008).

\subsection{Effect of flow distortion}

A CFD study of flow over the Oden was undertaken primarily in order to correct the wind measurements used to determine surface exchange coefficients from estimates of turbulent fluxes. Here we use the CFD model to examine the biases resulting from flow distortion over the lidar location. These calculations are not used as an active part of the lidar retrieval but rather as a means of assessing lidar data quality. A commercial CFD code, VECTIS (Ricardo, 2014), was used to model the three-dimensional flow over the Oden for a wide range of wind directions: every $10^{\circ}$ from bowon flow, through beam-on flow on both port and starboard sides. Additional runs were undertaken for flow from 120, 150 and $180^{\circ}$ from the bow. All runs used a $10 \mathrm{~m}$ wind speed of $7 \mathrm{~m} \mathrm{~s}^{-1}$, close to the campaign mean, with one additional (bow-on) run being undertaken for $U_{10}=15 \mathrm{~m} \mathrm{~s}^{-1}$. In the model the stratification is neutral, free-stream wind profiles are logarithmic with altitude and the far-field vertical velocity is zero. The model domain is centred on the ship and extends $1000 \mathrm{~m}$ in length, $1800 \mathrm{~m}$ in width, and $250 \mathrm{~m}$ in height. The number of computational cells within the domain was around 5 million. The cell size varied throughout the domain, with sizes of 0.12 to $0.25 \mathrm{~m}$ at the bow mast instrument location. This increased to around $20 \mathrm{~m}$ close to the edges of the domain. A grid independency study showed that a $50 \%$ reduction of cell sizes over the whole domain only resulted in a $1 \%$ change in wind speed bias with respect to the free-stream flow at the bow mast anemometer locations.

The ship imposes a significant obstacle to the flow and forces a strong vertical velocity in the lowest few tens of metres above the lidar, which varies with wind direction (Fig. 9a). This effect is slightly asymmetric about the bow because the lidar is situated towards the port side. At $75 \mathrm{~m}$, the lowest level of robust Doppler wind measurements, the vertical velocity varies from about 0.2 to $0.4 \mathrm{~m} \mathrm{~s}^{-1}$ for $U_{10}=$ $7 \mathrm{~m} \mathrm{~s}^{-1}$ and for wind directions for which the superstructure does not directly block the flow; this decreases approximately exponentially with altitude. The mean calculated vertical velocity above $75 \mathrm{~m}$ (roughly 3 times the obstacle height) is $0.04 \mathrm{~m} \mathrm{~s}^{-1}$ for flow onto the bow, increasing to a little over $0.12 \mathrm{~m} \mathrm{~s}^{-1}$ for beam-on flow. The CFD run with $U_{10}=15 \mathrm{~m} \mathrm{~s}^{-1}$ for bow-on flow showed vertical velocity approximately double that at $U_{10}=7 \mathrm{~m} \mathrm{~s}^{-1}$. The altitudedependent vertical wind speed behaviour derived from CFD 


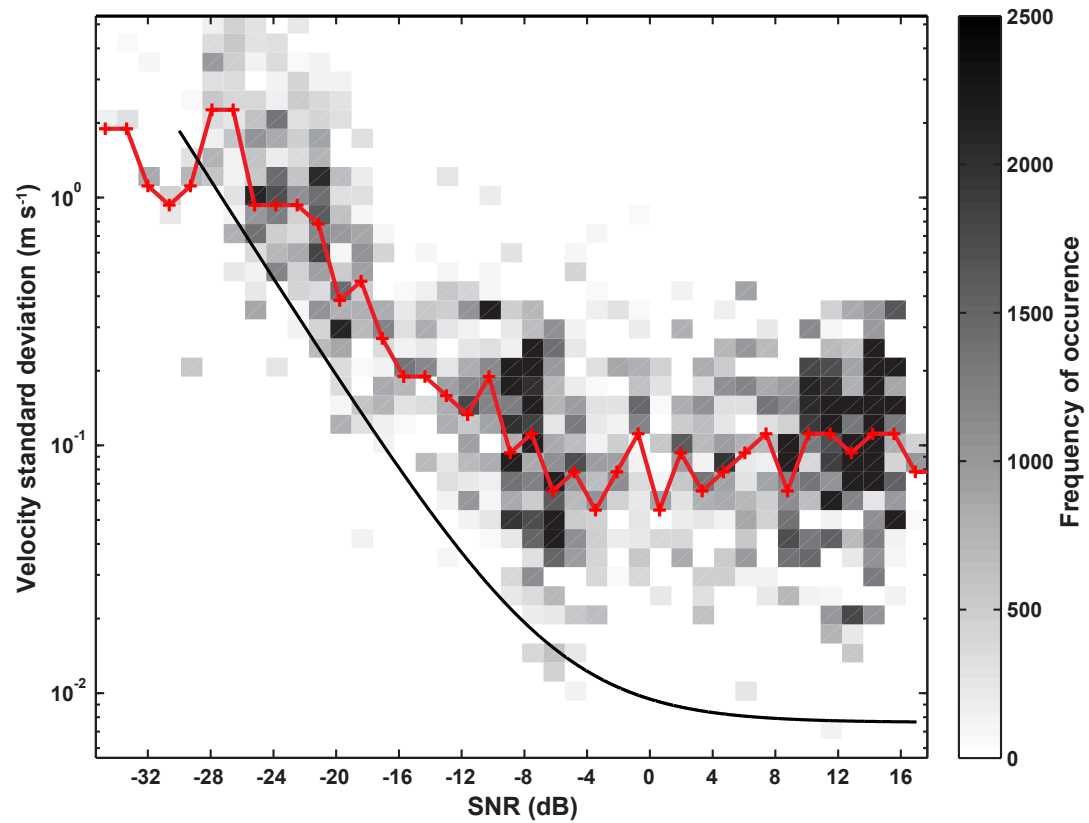

Figure 8. Standard deviations of the Doppler horizontal velocity determined from the zero lag impulse in the auto-covariance and the theoretical standard deviation (black line) for a signal spectral width of $2 \mathrm{~m} \mathrm{~s}^{-1}$. The median standard deviation per SNR bin is shown as a red line.
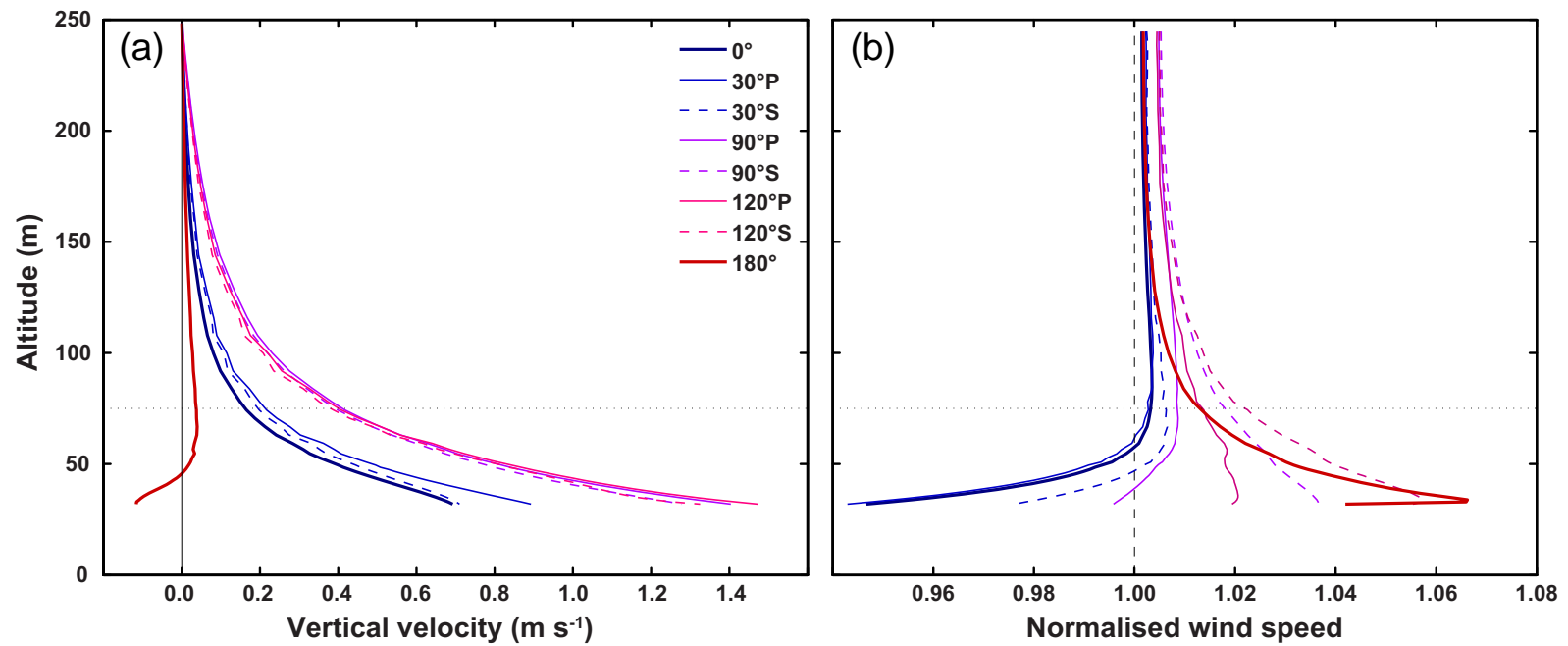

Figure 9. CFD study results for $U_{10}=7 \mathrm{~m} \mathrm{~s}^{-1}$, above the shipboard lidar location: (a) profiles of vertical velocity above the lidar for various wind directions (port and starboard, relative to the bow). (b) Profiles of the horizontal wind speed, normalised by the free-stream profile for various wind directions (port and starboard) with respect to the bow. The horizontal dotted line indicates $75 \mathrm{~m}$ above the surface, the lowest level of reliable Doppler velocity measurements. Data are shown only for altitude $>31.5 \mathrm{~m}$, the approximate level of the first lidar range gate.

modelling was also observed in the Doppler lidar measurements, though with smaller magnitude probably as a result of temporal averaging of turbulent motions and vertical smoothing.

The vertical velocity at the top of the model domain at $250 \mathrm{~m}$ is set to zero; in reality a small vertical velocity might extend above this level. The normalised difference between the horizontal wind speed and the far-field wind at the top of the domain is non-zero but less than $5 \%$ (Fig. 9b), whereas we would expect it to approach zero. This is due to the ship slightly constricting the flow within the domain. Overall the normalised bias (positive) in horizontal wind speed is less than $2 \%$ for all wind directions at altitudes above $75 \mathrm{~m}$. Note 
that the CFD model results apply to the mean flow only and do not account for potential effects on turbulent flow.

\section{Conclusions and summary}

We have presented Doppler lidar measurements made during the Arctic cruise of the icebreaker Oden in summer and autumn 2014. In contrast to earlier ship-borne observations in which data on ship motion were used to correct the alignment of the scanning unit of a Doppler lidar, we placed the instruments on a motion-stabilisation platform that enabled active stabilisation to within $0.3^{\circ}$ of horizontal most of the time. The comparison of the stabilised HALO Doppler lidar to radio soundings is comparable to that for land-based investigations (Barlow et al., 2011; Hirsikko et al., 2014; Päschke et al., 2015). Our results also compare well with previous ship-borne deployments of the HRDL Doppler lidar (Wolfe et al., 2007; Pichugina et al., 2012).

The fundamental measurement error of the lidar vertical wind speed was found to be in the range of 0.025 to $0.2 \mathrm{~m} \mathrm{~s}^{-1}$ for SNR above $-16 \mathrm{~dB}$, which is smaller than the discrepancy between the mean wind speed derived from lidar and radio soundings of $0.3 \mathrm{~m} \mathrm{~s}^{-1}$ (see Sect. 3.1). Overall, lidar measurements increase in reliability when the change in ship's heading within a $20 \mathrm{~s}$ measurement cycle is at a minimum. The measurement range during fog-free periods was limited primarily by low aerosol concentration limiting the backscatter in clear air; measurements were obtained up to an altitude of 1000 ma.s.l., and up to 3000 ma.s.l. when multiple layers of transparent clouds were present. Higher altitudes would be reached at midlatitudes, where atmospheric aerosol load is generally higher than in the Arctic (Wolfe et al., 2007; Pearson et al., 2009; Päschke et al., 2015). Data coverage was found to be comparable to previous land- and ship-based Doppler lidar observations. Ship-based Doppler lidar measurements provide a much more detailed, higher time-resolution view of atmospheric boundary layer processes than can be achieved with radiosondes. At sea and on other moving platforms, motion correction or stabilisation is necessary to derive reliable results from Doppler lidar measurements. Combining a commercial Doppler lidar with a custom-made motion-stabilisation platform as presented here forms a reliable and autonomous set-up that could be placed on commercial or research ships to provide measurements for a number of applications, including studies of marine boundary layer meteorology and air-sea interaction, wind mapping for proposed wind turbine installations, and validation of satellite retrievals such as that of the upcoming ADM-Aeolus (Atmospheric Dynamics Mission Aeolus) mission (ESA, 2008) that features a space borne Doppler lidar. The near-field biases induced by airflow distortion over the ship are potentially significant, but they can and should be accounted for via modelling studies. 


\section{Appendix A: Motion-correction algorithm}

Our determination of the residual linear velocity of the lidar follows the complementary filtering method of Edson et al. (1998). This utilises a "strap down" motion-sensing package that measures three-axis linear accelerations and angular rotation rates at high frequency (typically $\geq 10 \mathrm{~Hz}$ ) within the frame of reference of the instrument, along with the compass heading and horizontal velocity of the ship at low rate $(\leq 1 \mathrm{~Hz})$, derived from the ship's navigation data. In principle we require only the linear accelerations and compass heading here, since the platform is stabilised against pitch and roll; however, for the sake of completeness we implement the full calculation, summarised below.

In order to determine the high-frequency time-varying velocity, we first determine the instantaneous orientation of the platform, rotate the measured accelerations from the instrument frame of reference to the Earth frame, and integrate over time. The orientation of the platform is defined by a set of Euler angles: pitch $(\alpha)$, roll $(\beta)$, and yaw $(\gamma)-$ a set of rotations about non-orthogonal axes where each rotation is about one of the aces resulting from the previous rotation in a specific order. We use a right-handed Cartesian system with $x$ positive towards the bow, $y$ positive to port, and $z$ positive upward; roll, pitch, and yaw are then positive for righthanded rotations about the $x, y$, and $z$ axes, respectively. In the Earth frame the $x$ and $y$ axes are conventionally positive to east and north, and compass heading is a left-handed rotation; thus $\gamma=90^{\circ}$ heading. The orientation of the instrument with respect to the Earth frame is defined by applying the rotations in order: yaw, pitch, and roll; to transform the measurements back to the Earth frame, the opposite rotations are applied in reverse order, in vector notation:

$$
V=\mathbf{Y P R} V^{\prime},
$$

where $V$ is a vector quantity; the prime indicates the measurement frame; and $\mathbf{Y}, \mathbf{P}$, and $\mathbf{R}$ are the yaw, pitch, and roll matrices, respectively, defined for rotations from the measurement to the Earth frame as

$$
\begin{aligned}
& \mathbf{Y}=\left[\begin{array}{ccc}
\cos \gamma & -\sin \gamma & 0 \\
\sin \gamma & \cos \gamma & 0 \\
0 & 0 & 1
\end{array}\right], \\
& \mathbf{P}=\left[\begin{array}{ccc}
\cos \alpha & 0 & \sin \alpha \\
0 & 1 & 0 \\
-\sin \alpha & 0 & \cos \alpha
\end{array}\right], \\
& \mathbf{R}=\left[\begin{array}{ccc}
1 & 0 & 0 \\
0 & \cos \beta & -\sin \beta \\
0 & \sin \beta & \cos \beta
\end{array}\right] .
\end{aligned}
$$

$\alpha$ and $\beta$ can be obtained directly from the XSens motion pack, or they can be derived from the integration of the raw rotation rates about the $y$ and $x$ axes over time. To avoid accumulating errors from the integration of any bias or sensor noise, the time series are high-pass-filtered with a cosine roll-off between a passband limit of $1 / 60 \mathrm{~Hz}$ and stopband limit of $1 / 120 \mathrm{~Hz}$ (i.e. periods of 1 and $2 \mathrm{~min}$, respectively). The low-frequency components of pitch and roll are obtained from the low-pass-filtered components of gravity measured by the $x$ - and $y$-accelerometers as a result of their tilt from the horizontal; the filter has complementary pass- and stopband limits to the high-pass filter used above, i.e. a passband limit of $1 / 120 \mathrm{~Hz}$ and a stopband limit of $1 / 60 \mathrm{~Hz}$. The tilts of the $x$ and $y$ axes are given by $\theta=\sin ^{-1}(a / g)$, where $a$ is the measured acceleration (after low-pass filtering) and $g$ is gravity. The low-frequency contributions to the pitch and roll angles are then

$$
\begin{aligned}
& \alpha_{1 o}=\theta_{x} \\
& \beta_{\mathrm{lo}}=\sin ^{-1}\left[\frac{\sin \theta_{y}}{\cos \theta_{x}}\right] .
\end{aligned}
$$

For small tilts from the horizontal $\left(\theta<\approx 8^{\circ}\right)$ we can use the approximation $\beta_{\mathrm{lo}}=\theta_{y}$, introducing an error of less than $0.1^{\circ}$. The full pitch and roll angles are then obtained from the sum of high- and low-frequency contributions. The yaw angle is similarly obtained from the sum of the high-passfiltered rotation rate about the $z$ axis and the low-pass-filtered ship heading.

Having obtained the full pitch, roll, and yaw angles for each sample interval, the measured accelerations along sensor $x, y$, and $z$ axes are rotated into the Earth frame, highpass-filtered, and integrated to obtain the high-frequency velocity perturbations about the ship's mean motion. Strictly an additional linear velocity term should be added to account for any rotation of the sensing head about the motion pack, which will be unresolved by the accelerometers. However, the platform stabilisation means this term is approximately zero for pitch and roll rotations, and the yaw rotation rate is small so that the unresolved velocity is typically < $0.01 \mathrm{~m} \mathrm{~s}^{-1}$, negligibly small compared with the Doppler velocity resolution. The low-pass-filtered ship's velocity in the Earth frame is added to these to obtain the final velocity of the measurement platform.

The lidar Doppler velocity measurement is corrected by adding the component of the mean platform velocity along the direction of the beam. We first rotate the platform velocity back into the instrument reference frame,

$V_{\text {inst }}=\mathbf{R}^{\prime} \mathbf{P}^{\prime} \mathbf{Y}^{\prime} V$

and then into a reference frame aligned with the lidar beam. The relative pitch and yaw angles are the negative of the lidar's elevation and azimuth angles, and roll is zero. The rotation matrices are calculated as in Eq. (A2), and the velocity in the beam's frame of reference is

$$
\boldsymbol{V}_{\text {beam }}=\mathbf{P}^{\prime} \mathbf{Y}^{\prime} V_{\text {inst }} .
$$

The velocity along the beam is then simply the first $(x)$ components of the $\boldsymbol{V}_{\text {beam }}$ vector. 
Acknowledgements. ACSE was supported by funding from the Knut and Alice Wallenberg Foundation, Swedish Research Council, Faculty of Science at Stockholm University, US Office of Naval Research, the US National Oceanic and Atmospheric Administration (NOAA), and the UK Natural Environment Research Council (grant No. NE/K011820/1). The lidar and the radio sounding system were supplied by the Atmospheric Measurement Facility of the UK National Centre for Atmospheric Science. We are grateful to the Swedish Polar Research Secretariat and to the two captains and crews of the Oden for logistics support.

Edited by: G. Baumgarten

\section{References}

Baker, W. E., Atlas, R., Cardinali, C., Clement, A., Emmitt, G. D., Gentry, B. M., Hardesty, R. M., Källén, E., Kavaya, M. J., Langland, R., Ma, Z., Masutami, M., McCarty, W., Pierce, R. B., Pu, Z., Riishojgaard, L. P., Ryan, J., Tucker, S., Weissmann, M., and Yoe, J. G.: Lidar-measured wind profiles: the missing link in the global observing system, B. Am. Meteorol. Soc., 95, 543-564, 2014.

Barlow, J. F., Dunbar, T. M., Nemitz, E. G., Wood, C. R., Gallagher, M. W., Davies, F., O'Connor, E., and Harrison, R. M.: Boundary layer dynamics over London, UK, as observed using Doppler lidar during REPARTEE-II, Atmos. Chem. Phys., 11, 2111-2125, doi:10.5194/acp-11-2111-2011, 2011.

Birch, C. E., Brooks, I. M., Tjernström, M., Shupe, M. D., Mauritsen, T., Sedlar, J., Lock, A. P., Earnshaw, P., Persson, P. O. G., Milton, S. F., and Leck, C.: Modelling atmospheric structure, cloud and their response to $\mathrm{CCN}$ in the central Arctic: ASCOS case studies, Atmos. Chem. Phys., 12, 3419-3435, doi:10.5194/acp-12-3419-2012, 2012.

Brooks, I. M.: Spatially distributed measurements of platform motion for the correction of ship-based turbulent fluxes, J. Atmos. Ocean. Tech., 25, 2007-2017, 2008.

Dee, D. P., Uppala, S. M., Simmons, A. J., Berrisford, P., Poli, P., Kobayashi, S., Andrae, U., Balmaseda, M. A., Balsamo, G., Bauer, P., Bechtold, P., Beljaars, A. C. M., van de Berg, L., Bidlot, J., Bormann, N., Delsol, C., Dragani, R., Fuentes, M., Geer, A. J., Haimberger, L., Healy, S. B., Hersbach, H., Hólm, E. V., Isaksen, L., Kållberg, P., Köhler, M., Matricardi, M., McNally, A. P., Monge-Sanz, B. M., Morcrette, J.-J., Park, B.K., Peubey, C., de Rosnay, P., Tavolato, C., Thépaut, J.-N., and Vitart, F.: The ERA-Interim reanalysis: configuration and performance of the data assimilation system, Q. J. Roy. Meteor. Soc., 137, 553-597, 2011.

Drennan, W., Graber, H., Collins III, C., Herrera, A., Potter, H., Ramos, R., and Williams, N.: EASI: an air-sea interaction buoy for high winds, J. Atmos. Ocean. Tech., 31, 1397-1409, 2014.

Edson, J. B., Hinton, A. A., Prada, K. E., Hare, J. E., and Fairall, C. W.: Direct covariance flux estimates from mobile platforms at sea*, J. Atmos. Ocean. Tech., 15, 547-562, 1998.

ESA: ADM-Aeolus Science Report, available at: http: //www.esa.int/Our_Activities/Observing_the_Earth/The_ Living_Planet_Programme/Earth_Explorers/ADM-Aeolus (last access: 18 August 2015), 2014.
Frehlich, R.: Estimation of velocity error for Doppler lidar measurements, J. Atmos. Ocean. Tech., 18, 1628-1639, 2001.

Grubbs, F. E.: Procedures for detecting outlying observations in samples, Technometrics, 11, 1-21, 1969.

Heintzenberg, J. and Leck, C.: The summer aerosol in the central Arctic 1991-2008: did it change or not?, Atmos. Chem. Phys., 12, 3969-3983, doi:10.5194/acp-12-3969-2012, 2012.

Hill, R., Brewer, W. A., and Tucker, S.: Platform-Motion Correction of Velocity Measured by Doppler Lidar, J. Atmos. Ocean. Tech., 25, 1369-1382, 2007.

Hirsikko, A., O'Connor, E. J., Komppula, M., Korhonen, K., Pfüller, A., Giannakaki, E., Wood, C. R., Bauer-Pfundstein, M., Poikonen, A., Karppinen, T., Lonka, H., Kurri, M., Heinonen, J., Moisseev, D., Asmi, E., Aaltonen, V., Nordbo, A., Rodriguez, E., Lihavainen, H., Laaksonen, A., Lehtinen, K. E. J., Laurila, T., Petäjä, T., Kulmala, M., and Viisanen, Y.: Observing wind, aerosol particles, cloud and precipitation: Finland's new groundbased remote-sensing network, Atmos. Meas. Tech., 7, 13511375, doi:10.5194/amt-7-1351-2014, 2014.

Houchi, K., Stoffelen, A., Marseille, G., and De Kloe, J.: Comparison of wind and wind shear climatologies derived from highresolution radiosondes and the ECMWF model, J. Geophys. Res.-Atmos., 115, D22123, doi:10.1029/2009JD013196, 2010.

Landwehr, S., O'Sullivan, N., and Ward, B.: Direct flux measurements from mobile platforms at sea: motion and air-flow distortion corrections revisited, J. Atmos. Ocean. Tech., 32, 1163$1178,2015$.

Lane, S., Barlow, J. F., and Wood, C. R.: An assessment of a threebeam Doppler lidar wind profiling method for use in urban areas, J. Wind Eng. Ind. Aerod., 119, 53-59, 2013.

Lannefors, H., Heintzenberg, J., and Hansson, H. C.: A comprehensive study of physical and chemical parameters of the Arctic summer aerosol; results from the Swedish expedition Ymer-80, Tellus B, 35, 40-54, 1983.

Marlton, G. J.; Harrison, R. G., Nicoll, K. A., and Williams, P. D.: Note: A balloon-borne accelerometer technique for measuring atmospheric turbulence, Rev. Sci. Instrum., 86, 016109, doi:10.1063/1.4905529, 2015.

McGillis, W. R., Edson, J. B., Hare, J. E., and Fairall, C. W.: Direct covariance air-sea $\mathrm{CO}_{2}$ fluxes, J. Geophys. Res.-Oceans, 106, 16729-16745, 2001.

Moat, B. I. and Yelland, M. J.: Going with the flow: state of the art marine meteorological measurements on the new NERC research vessel, Weather, 63, 158-159, 2008.

Moat, B. I., Yelland, M. J., Pascal, R. W., and Molland, A. F.: An overview of the airflow distortion at anemometer sites on ships, Int. J. Climatol., 25, 997-1006, 2005.

Moat, B. I., Yelland, M. J., and Molland, A. F.: Quantifying the airflow distortion over merchant ships. Part II: Application of the model results, J. Atmos. Ocean. Tech., 23, 351-360, 2006a.

Moat, B. I., Yelland, M. J., Pascal, R. W., and Molland, A. F.: Quantifying the airflow distortion over merchant ships. Part I: Validation of a CFD model, J. Atmos. Ocean. Tech., 23, 341-350, 2006 b.

Norris, S. J., Brooks, I. M., Hill, M. K., Brooks, B. J., Smith, M. H., and Sproson, D. A. J.: Eddy covariance measurements of the sea spray aerosol flux over the open ocean, J. Geophys. Res.-Atmos., 117, d07210, doi:10.1029/2011JD016549, 2012. 
O’Connor, E. J., Illingworth, A. J., Brooks, I. M., Westbrook, C. D., Hogan, R. J., Davies, F., and Brooks, B. J.: A method for estimating the turbulent kinetic energy dissipation rate from a vertically pointing Doppler lidar, and independent evaluation from balloon-borne in situ measurements, J. Atmos. Ocean. Tech., 27, 1652-1664, 2010.

Päschke, E., Leinweber, R., and Lehmann, V.: An assessment of the performance of a $1.5 \mu \mathrm{m}$ Doppler lidar for operational vertical wind profiling based on a 1-year trial, Atmos. Meas. Tech., 8, 2251-2266, 2015,

http://www.atmos-meas-tech.net/8/2251/2015/.

Pearson, G., Davies, F., and Collier, C.: An analysis of the performance of the UFAM pulsed Doppler lidar for observing the boundary layer, J. Atmos. Ocean. Tech., 26, 240-250, 2009.

Pichugina, Y. L., Banta, R. M., Brewer, W. A., Sandberg, S. P., and Hardesty, R. M.: Doppler lidar-based wind-profile measurement system for offshore wind-energy and other marine boundary layer applications, J. Appl. Meteorol. Climatol., 51, 327-349, 2012.

Prytherch, J., Yelland, M. J., Brooks, I. M., Tupman, D. J., Pascal, R. W., Moat, B. I., Norris, S. J.: Motion-correlated flow distortion and wave-induced biases in air-sea flux measurements from ships, Atmos. Chem. Phys., 15, 10619-10629, doi:10.5194/acp-15-10619-2015, 2015.

Ricardo: VECTIS Computational Fluid Dynamics (Release 2014.2) users guide, Tech. rep., Ricardo Software Ltd., UK, available at: http://www.software.ricardo.com/support/manuals/ vectis/pdfs/2014.2/VECTIS_2014.2_Manual.pdf (last access: 3 August 2015), 2014.

Schween, J. H., Hirsikko, A., Löhnert, U., and Crewell, S.: Mixinglayer height retrieval with ceilometer and Doppler lidar: from case studies to long-term assessment, Atmos. Meas. Tech., 7, 3685-3704, 2014, http://www.atmos-meas-tech.net/7/3685/2014/.

Tjernström, M., Shupe, M. D., Brooks, I. M., Persson, P. O. G., Prytherch, J., Salisbury, D. J., Sedlar, J., Achtert, P., Brooks, B. J., Johnston, P. E., Sotiropoulou, G., and Wolfe, D.: Warm-air advection, air mass transformation and fog causes rapid ice melt, Geophys. Res. Lett., 42, 5594-5602, 2015.
Tucker, S. C., Senff, C. J., Weickmann, A. M., Brewer, W. A., Banta, R. M., Sandberg, S. P., Law, D. C., and Hardesty, R. M.: Doppler lidar estimation of mixing height using turbulence, shear, and aerosol profiles, J. Atmos. Ocean. Tech., 26, 673-688, 2009.

VAISALA: Radiosonde RS92-SGP, data sheet, available at: http: //www.vaisala.com/Vaisala\%20Documents/Brochures\%20and\% 20Datasheets/RS92SGP-Datasheet-B210358EN-F-LOW.pdf, last access: 19 April 2015.

Werner, C.: Doppler Wind Lidar, edited by: Weitkamp, Springer, New York, 325-353, 2005.

WMO: Statement of guidance for global numeric weather prediction (NWP), available at: www.wmo.int/pages/prog/www/OSY/ GOS-RRR.html (last access: 30 June 2015), 2014.

Wolfe, D. E., Brewer, W. A., Tucker, S. C., White, A. B., White, D. E., Welsh, D. C., Ruffieux, D., Fairall, C. W., Ratterree, M., Intrieri, J. M., McCarty, B. J., and Law, D. C.: Shipboard multisensor merged wind profiles from the New England Air Quality Study 2004, J. Geophys. Res.-Atmos., 112, d10S15, doi:10.1029/2006JD007344, 2007.

Yang, M., Blomquist, B. W., and Nightingale, P. D.: Air-sea exchange of methanol and acetone during HiWinGS: Estimation of air phase, water phase gas transfer velocities, J. Geophys. Res.Oceans, 119, 7308-7323, 2014.

Yelland, M., Moat, B. I., Taylor, P. K., Pascal, R. W., Hutchings, J., and Cornell, V. C.: Wind stress measurements from the open ocean corrected for airflow distortion by the ship, J. Phys. Oceanogr., 28, 1511-1526, 1998.

Yelland, M., Moat, B., Pascal, R., and Berry, D.: CFD model estimates of the airflow distortion over research ships and the impact on momentum flux measurements, J. Atmos. Ocean. Tech., 19, 1477-1499, 2002. 